\title{
Quantitative Analysis and Evaluation of the Teaching Process based on Information Entropy
}

\author{
Xixi QU ${ }^{1,2}$, Yueguang XIE ${ }^{1}$, Jiaqi LIN $^{2}$ \\ 1. Information and Software Engineering Institute, Northeast Normal University, Changchun 130024,China \\ 2. Modern Educational Technology Center, Harbin University of Science and Technology, Harbin 150080, \\ China
}

\begin{abstract}
The teaching process is one of the important factors in the classroom teaching reform and teaching evaluation activities, and its related research is important for improving teaching practice. In this paper, the teaching process as a starting point, on the basis of Flanders scale , we improve the scale and use the information entropy to evaluate the process of classroom teaching, and explain its value in teaching and research .The purpose is to provide a theoretical basis of objective, impartial evaluation for the teacher's classroom teaching activities.
\end{abstract}

KEYWORD: Teaching process, Quantification, VICS, Information entropy

\section{INTRODUCTION}

Education is a complex social phenomenon, there are a variety of laws in different levels and scope. Only by conducting educational research in order to recognize and grasp these laws, in order to make the educational experience rise to the scientific theory of education. Level of Education Research to some extent depends on The scientific research methods. Therefore, to master the correct method of study, understand the whole process of education and scientific research has important theoretical and practical significance to improve the education and scientific research level.

Quantitative research method of educational research is a mathematical tool to gather and process research data in education and scientific research. It is one of the important methods to carry out education and research activities. In practical education and research process, choosing a reasonable quantitative research methods plays an important role in research. Reasonable advanced quantitative research methods can comprehensively and objectively and accurately describe the phenomenon and laws of Education. Reasonable advanced quantitative research methods can play the greatest degree of data effectiveness. Reasonable advanced quantitative research methods can deeply mine the hidden regularities behind complex phenomena of education, can play a multiplier effect. [1]

About quantify, simply put, is to be digitized, which uses figures illustrate the problem.[1]
Quantization is a method of using mathematical tools to collect and process research data. [2]

Quantitative research which has the following features:

1. Objectivity: With the digital description of things than the use of language is more intuitive, more convincing, namely "Facts speak louder than words".

2. Accuracy: Digital portray something more accurate than using the language.

3. Extensiveness: Quantitative research is often built on the lot on the basis of statistical sampling, compared with case studies, quantitative research results more extensive, more convincing.

4. Profound: Quantization level of a discipline often on behalf of the level of development of the discipline, and the use of quantitative methods can reflect the teacher's level of profound research.

5. Popularity: Quantitative research of educational research at home and abroad more and more attention from educators, First of all not knowing quantitative research means cannot read research articles written by someone else and it is impossible to absorb the findings of others. [1]

6. Quantification method is also the data basis of obtaining important theory.

Due to the above quantitative research has some characteristics, so it has gradually become a new trend in teaching research methods, causing more and more researchers' attention. 


\section{THEORETICAL BASIS FOR ENTROPY}

\subsection{Entropy and Information Entropy}

Entropy comes from the physics and it is a basic concept of the second law of thermodynamics which is proposed by the German physicist Clausius in 1865. Although entropy in thermodynamics and in information theory has the same mathematical form, they are not directly linked. Here we do not do too much introduction, only focuses on theory in information.

Probabilistic systems provided there are $\mathrm{n}$ events, the probability of each event is generated : pi $(\mathrm{i}=1 \sim \mathrm{n})$. When the event I occurs, the amount of information given to us :Hi=-log2pi.For the probability of the system consisting of $n$ events, the average amount of information generated for each event: $\mathrm{H}=-\sum_{i=1}^{n} \mathrm{p}_{i} \log _{2} p_{i}$, which we call information entropy, referred to as the entropy.[3] When the probability of each variable in the system is equal, the system has the maximum entropy called Hmax.

\subsection{Meaning of information entropy}

According to people's experience, information quantity that a event gives people is related to probability of occurrence of this event (the possibility). The occurrence of small probability event gives the amount of information to people. In contrast, the occurrence of big probability event gives less information to people.

Information entropy characterizing the statistical characteristics of the system as a whole, is a measure of the uncertainty of the overall average. For a particular system, which has only one information entropy. For example, two systems, which are two of the number of variables, the probability respectively:

$$
\left[X, P\left(X_{i}\right)\right]=\left[\begin{array}{cc}
x_{1} & x_{2} \\
0.990 .01
\end{array}\right], \quad\left[Y, P\left(Y_{i}\right)\right]=\left[\begin{array}{ll}
y_{1} & y_{2} \\
0.50 .5
\end{array}\right]
$$

so the information entropy:

$$
\begin{aligned}
& H(X)=-0.99 \log 0.99-0.01 \log 0.01=0.08 \text { bit } \\
& H(Y)=-0.5 \log 0.5-0.5 \log 0.5=1 \text { bit }
\end{aligned}
$$

The understanding of the information entropy (1): $\mathrm{H}(\mathrm{Y})>\mathrm{H}(\mathrm{X})$, This shows the average uncertainty of system $\mathrm{Y}$ is larger than system $\mathrm{X}$, that is ,before the incident, due to events $\mathrm{y} 1, \mathrm{y} 2$ are equal probability, it is difficult to guess which events occur in system Y; in system $\mathrm{X}$, although there are uncertainties, generally you can know that the possibility of $\mathrm{x} 1$ appears to be larger. Just as two football matches, one of which was the two sides are evenly matched; the other match, a big difference in strength between the two sides. Of course, people want to see the first, because the dubious, once finish, people get a large amount of information. That is how much Entropy is proportional to the amount of information.

The understanding of the information entropy(2): Information entropy $\mathrm{H}(\mathrm{X})$ characterized randomness of variable $X$. In the above example, for the variable $\mathrm{Y}$ taking $\mathrm{y} 1$ and $\mathrm{y} 2$ are equal probability, so its randomness is bigger; Probability variable $\mathrm{x} 1$ is much larger than $\mathrm{x} 2$, then the randomness of variable $\mathrm{X}$ is small. That is, information entropy reflects the randomness of variables, the greater the value, the greater the randomness of the system variables, the more flexible.

From the calculation formula of entropy we can easily see that the computing of information entropy is related to the number of variables in the systems. So it does not help us to take comparison of entropy in systems with different number of variables. If you want to compare their entropy, we can use the relative information entropy $h=H / H m a x$ to represent. The calculation of relative information entropy is beneficial for us to compare the information entropy of different systems.

\subsection{Redundancy}

Based on relative information entropy, we call $r=1$ $\mathrm{H} / \mathrm{Hmax}$ for redundancy. About the size of redundancy, there is no strict definition. High redundancy language is well structured, accurate in language information and has strong error correction capability. Because of refining, low redundancy language is good for coding, information transmission and oral and written expression are more flexible. The experts estimated that the upper limit of the English redundancy is $80 \%$, the lower limit is $67 \%$, with an average of 73 percent.[5] English is a kind of language with low transmission efficiency. Redundancy represents the proportion of passing information which is unnecessarily lengthy section. In the transmission of information, redundancy reduces the efficiency of information transmission. Of course, the redundancy is not always meaningless. As long as the effective use ,it is also very significant to the information prediction and error correction. Therefore, using information entropy to analyze the process of classroom teaching is an effective way to quantify the classroom evaluation.[6]

Here's a lesson of classroom information for as a practical example. Course Title: Educational Technology. Through the introduction of the concept of information entropy to the actual teaching process, we give specific quantitative analytical method related to information entropy and redundancy of the teaching process and further illustrate the important role of information entropy in the teaching process analysis, so as to provide a 
more reliable factual basis for evaluation of the teaching, teaching reform and other research activities.

\section{CLASSROOM INFORMATION PROCESSING}

\subsection{Data collection}

The data of educational research has two notable features: randomness and statistical regularity. Sources of data: a live teaching video.

\subsection{Processing and analysis of data: class information entropy calculation and analysis}

\subsubsection{Processing method}

According to VICS (Verbal Interaction Category System) classification system.[7]

VICS (Verbal Interaction Category System) classification system is developed by Edmund Amidon and Ned Flanders in 1967. It is divided into eleven categories: teacher activity (1-5), student activity(6-9), Silence and chaos, The detailed contents as listed in the following table 1.

Table 1. The original classification system based on the VICS

\begin{tabular}{|c|c|}
\hline Category & Content \\
\hline 1 & Teacher information display \\
\hline 2 & Teacher's instructions \\
\hline 3 & Teacher's questions \\
\hline 4 & Teacher accept students' view \\
\hline 5 & Teacher refuse students' view \\
\hline 6 & Students speak to teachers \\
\hline 7 & Students speak to other students \\
\hline 8 & Students reaction to the teacher \\
\hline 9 & Student reaction to other students \\
\hline 10 & Silence \\
\hline 11 & Chaos \\
\hline
\end{tabular}

Table2. The modified classification system based on the VICS

\begin{tabular}{|l|l|}
\hline Category & Content \\
\hline 1 & Teacher information display \\
\hline 2 & Teacher's prompt (inspiration or manuduction) \\
\hline 3 & Teacher's questions \\
\hline 4 & Teacher's encouragement and praise \\
\hline 5 & Teachers use multimedia \\
\hline 6 & Teacher-student dialogue (Instantaneous interaction) \\
\hline 7 & Students answer \\
\hline 8 & Students ask questions \\
\hline 9 & Students discuss \\
\hline 10 & Teacher's blackboard writing \\
\hline 11 & Students'reading.practice and operation \\
\hline 12 & Interest Case(poetry, story) \\
\hline 13 & Teacher's Evaluation \\
\hline 14 & Silence and Chaos \\
\hline
\end{tabular}

Due to its classification rigidly adhered to the traditional teaching, analysts can according to the purpose of the analysis, combined with modern teaching methods, teaching theory, learning theory and multiple teaching modes, modify and supplement the classification system of VICS.(Table 2).

\subsubsection{Data collection: a 45-minute video clips of classroom teaching.}

For the results of the sampling data is accurate, not too long sampling interval and the sampling data should not be excessive. Therefore, 15-second intervals for 25 minutes (interception) classroom teaching video classified sampling, a total of 100 data samples.

\subsubsection{Data processing using table 2}

(1)Recording teacher's and students' speech and behavior data at every 15-second interval (With the corresponding figures represent) (table 3 )

Table 3 classification data series

\begin{tabular}{|c|c|c|c|c|c|c|c|c|c|}
\hline 1 & 10 & 1 & 3 & 1 & 1 & 1 & 5 & 1 & 2 \\
\hline 7 & 1 & 2 & 1 & 4 & 1 & 5 & 1 & 3 & 1 \\
\hline 14 & 14 & 7 & 7 & 1 & 1 & 1 & 1 & 1 & 2 \\
\hline 3 & 1 & 1 & 6 & 1 & 1 & 1 & 2 & 3 & 2 \\
\hline 2 & 2 & 1 & 6 & 1 & 1 & 1 & 1 & 3 & 2 \\
\hline 2 & 1 & 1 & 1 & 6 & 1 & 3 & 4 & 7 & 7 \\
\hline 2 & 7 & 6 & 7 & 6 & 7 & 7 & 6 & 6 & 4 \\
\hline 7 & 7 & 7 & 7 & 4 & 2 & 2 & 7 & 4 & 1 \\
\hline 1 & 3 & 14 & 14 & 7 & 7 & 2 & 2 & 9 & 9 \\
\hline 7 & 7 & 4 & 1 & 6 & 1 & 1 & 1 & 1 & 1 \\
\hline
\end{tabular}

(2)Data Processing: Using SPSS (a kind of data statistical software), calculate the information entropy (table 4) and proportional distribution histograms of teacher-student activities (Figure 1)

Table 4 Data processing table

\begin{tabular}{|l|l|l|l|}
\hline Teaching activities & Frequency & $\begin{array}{l}\text { Probabilit } \\
\text { y }\end{array}$ & $\begin{array}{l}\text { Frequency } \\
\text { multiplication }\end{array}$ \\
\hline 1. teacher explain & 38 & .38000 & -.53045 \\
\hline 2.Teacher prompt & 14 & .14000 & -.39711 \\
\hline 3.Teacher questions & 7 & .07000 & -.26856 \\
\hline $\begin{array}{l}\text { 4.Encourage and } \\
\text { recognition }\end{array}$ & 6 & .06000 & -.24353 \\
\hline 5. Use Media & 2 & .02000 & -.11288 \\
\hline $\begin{array}{l}\text { 6.Instantaneous } \\
\text { interaction }\end{array}$ & 8 & .08000 & -.29151 \\
\hline 7.Students answer & 18 & .18000 & -.44531 \\
\hline 8. Students ask & 0 & .00000 & .00000 \\
\hline 9.Students' discuss & 2 & .02000 & -.11288 \\
\hline $\begin{array}{l}\text { 10.Teacher's } \\
\text { blackboard writing }\end{array}$ & 1 & .01000 & -.06644 \\
\hline $\begin{array}{l}\text { 11.Students' } \\
\text { operations }\end{array}$ & 0 & .00000 & .00000 \\
\hline 12. Interest Case & 0 & .00000 & .00000 \\
\hline $\begin{array}{l}\text { 13.Teacher's } \\
\text { Evaluation }\end{array}$ & 0 & .00000 & .00000 \\
\hline 14. Silence & 4 & .04000 & -.18575 \\
\hline
\end{tabular}

Total frequency $\mathrm{N}=100$, Information entropy 
$H=-\sum_{i=1}^{n} p_{i} \log _{2} p_{i}=2.65442$,

Redundancy $r=1-H / H \max =31 \%$

Proportional distribution histograms of teacherstudent activities (Figure 1)

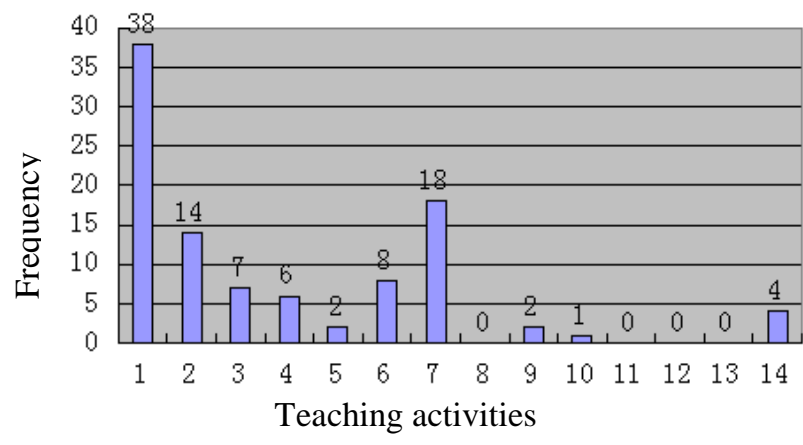

Fig1. Data processing

\subsubsection{Analysis of the data and the classroom}

As can be seen from Figure 1:

(1)Analysis of class structure

The proportion of teachers' language $=$ Section 1.2.3.4. number / total number $=(38+14+7+6) / 100$ $=65 \%$

The proportion of teachers 'behavior $=$ Section5.10. number $/$ total number $=(2+1) / 100=3 \%$

The proportion of students' language $=$ Section7.9. number / total number $=(18+2) / 100=20 \%$

The proportion of students' behavior $=$ Section 11 . number $/$ total number $=0 \%$

The proportion of invalid classroom $=$ Section 14 . number $/$ total number $=4 \%$

The proportion of media operations $=$ Section5. number $/$ total number $=2 \%$

The proportion of teacher-student interaction $=$ Section6. number $/$ total number $=8 \%$

Based on the above proportion, we see the ratio of teachers -students in a lesson in activities: Teacher Activities 68\%(65\%+3\%), Student Activities 20\%, shown in Figure 2:

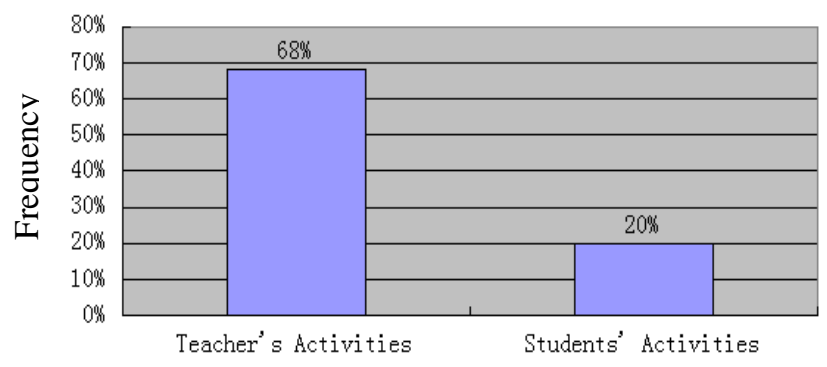

Fig 2. The proportion of teacher-student activities

Thus, we can objectively and accurately calculate the student-teacher proportion of time arrangements in a lesson. We can determine whether it reflects development of students in the reform of classroom teaching, whether it creat a relaxed and harmonious learning environment, stimulates students' interest in learning, develops students' question consciousness , emphasis on teaching the operation and activities, encourages students to take an active part, allows students to actively explore and so on. All these provide an accurate judgments basis for teaching evaluation and teaching reform.

(2)From the teacher's point of view, teacher's activity accounted for the total behavior frequency $68 \%$ and this shows that the whole class, teacher-led and the teacher is good at encouraging and praising the students $(2,4$ items accounted for $20 \%)$ which is mainly due to the teacher's personal teaching style and from the point of view of psychology and pedagogy, which is conducive to the establishment of the students valuable confidence. Teachers' questions and tips respectively accounted for $7 \%$ and $14 \%$ and Writing on the blackboard accounted for $1 \%$.

(3)From the students' point of view, students' activity accounted for the total behavior frequency $20 \%$,this shows that students fully participate in the whole process of teaching. In the teacher imparting knowledge, students are not passive absorption, but in the teacher's tips and encouragement to discover alone, thinking, construct. Teacher-student interaction rate of $8 \%$ which is one of the highlights of this lesson. Because of the selection of this lesson which is a theory course, the students operation behavior is zero.

(4)The actual classroom information entropy $\mathrm{H}=2.65442$, Redundancy $\mathrm{r}=1-\mathrm{H} / \mathrm{Hmax}=31 \%$.In this lesson, there are fourteen types of activities. According to the formula of entropy, if the probability of fourteen appeared evenly distributed, the maximum entropy Hmax $=3.83$. According to the meaning of entropy, the actual information entropy of class 2.65442 (slightly smaller than the maximum), we can clearly draw: Because the size of information entropy is proportional to the amount of information, so the classroom has a high amount of knowledge transmission and knowledge information. Information entropy also reflects the randomness of variables. The fourteen activities probability distribution is uniform, and the larger the value, the greater the variables randomness, the more flexible, the more changeable the teacher and student activities, the more diversified the instruction form. Low redundancy $31 \%$ and high transmission efficiency of knowledge.

\subsection{Conclusions}

Through the above quantitative analysis of the teaching process of entropy, we can provide the evidence and information on the following aspects for classroom teaching reform and teaching evaluation in the new curriculum background:

(1) The amount of information in the teaching process; 
(2) Flexibility of teaching activities in the teaching process ;

(3) The efficiency of information transmission in the teaching process ;

(4) The proportion of time of teacher's and students' behavior in the teaching process;

(5) By modifying the VICS different classification, you can also analyze the different aspects of teacher lecture style.

\section{SUMMARY}

Education data has two characteristics of randomness and statistical regularities. Thus researchers are required to seek the characteristics and laws of the research object in the numerous and complicated data, which is the main content of quantitative research. Quantification of educational information also greatly enriches the theory and practice about the teaching evaluation and solves the scientificity of teaching evaluation and the level of evaluation study. At the same time, quantitative research method is the best way to carry out education and research, is popular at home and abroad and the future trend of development. Currently, there are more mathematical method to be further introduced into the processing and analysis of educational information. For example, the concept of entropy will be further used in other aspects of education, quantitative analysis of the teaching mode, matrix and analysis method of fuzzy mathematics etc. To further analyze these quantitative research methods, to improve the understanding of the status and role of quantitative research methods in education and research, there is still a long way to go.

\section{REFERENCES}

[1] Tongqingwei, Huyingbin, Sunqian. Quantitative methods in Educational Research. Beijing: China Science and Technology Press ,1997: 2-9.(1997)

[2] Likedong, The research methods of Educational Technology. Beijin: Beijing Normal University Press, 2003: 21.(2003)

[3] Fuderong, Zhanghuimin. Educational information processing. Beijing: Beijing Normal University Press, 2003: 46-51.(2003)

[4] Information entropy theory http://wenku.baidu.com/view/17370d287375a417866f8f02. html(2014-03-30).

[5] Zhengnansheng, The study of Chinese information redundancy. Nanchang University, 2008.12 (2008)

[6] Liwanchun, Zhuyundong, Liuchaoli, Quantitative evaluation model based on information entropy of classroom teaching, Audio-visual education research, 2009.1: 99-102(2009)

[7] Bob Roost, B11 Interaction Analyzed in Traditional and Satellite-Delivered Extension Educational Presentations1 Journal Extension1 2000.11 